\title{
Particle Swarm Optimization for the Path Loss Reduction in Suburban and Rural Area
}

\author{
Messaoud Garah ${ }^{1}$, Houcine Oudira ${ }^{2}$, Lotfi Djouane ${ }^{3}$, Nazih Hamdiken ${ }^{4}$ \\ ${ }^{1,2,3}$ Electronic Departement, University Mohamed Boudiaf- M'Sila, Algeria \\ ${ }^{4}$ Electronic Departement, University of- Batna, Algeria
}

\begin{tabular}{l} 
Article Info \\
\hline Article history: \\
Received Jan 18, 2017 \\
Revised Mar 21, 2017 \\
Accepted Apr 13, 2017 \\
\hline
\end{tabular}

Keyword:

Empirical models

Obtimization

Path loss

PSO algorithm

\begin{abstract}
In the present work, a precise optimization method is proposed for tuning the parameters of the COST231 model to improve its accuracy in the path loss propagation prediction. The Particle Swarm Optimization is used to tune the model parameters. The predictions of the tuned model are compared with the most popular models. The performance criteria selected for the comparison of various empirical path loss models is the Root Mean Square Error (RMSE). The RMSE between the actual and predicted data are calculated for various path loss models. It turned out that the tuned COST 231 model outperforms the other studied models.
\end{abstract}

Copyright $@ 2017$ Institute of Advanced Engineering and Science. All rights reserved.

\section{Corresponding Author:}

Messaoud Garah,

Faculty of Technology, Electronic Departement,

University Mohamed Boudiaf- M'Sila,

Université Med BOUDIAF-BP 166 M'sila 28000, Algeria.

Email: messa.gareh@gmail.com

\section{INTRODUCTION}

The need for connectivity anywhere, added to the increment in the number of users, has triggered the development of various generations of mobile communication standards in the last decades. The demand for greater traffic capacity involving both voice and data transmission requires the planning of mobile communication networks comprised of smaller and smaller cells, thus making the number of base stations grow exponentially, and complicating the process of determining and optimizing the location of these stations. Because of this, accurate and fast prediction models are needed for making received signal level/path loss predictions prior to actual network deployment [1], [2].

In this paper, we analyze the performance achievable with an intermediate technique, between purely empirical models [3], [4] and real measure established from the field of study, based on the use of Particle Swarm Optimization.

In the last few years, many researchers have applied several techniques for predicting the path loss environments [5-7]. In the above references, extensive descriptions and GA optimizations and other methods, have been presented. However, optimized model can provide optimal parameters for radio-wave path-loss predicting in the target area. This is the main issue discussed in this paper.

The rest of this paper is organized as follows. In section 2 and 3 we review each empirical model and the PSO method. section 4 presents the application, results and discussion. Finally, in the last section we present our conclusion. 


\section{PARTICLE SWARM OPTIMIZATION}

The Particle swarm optimization is a population-based algorithm for searching global optimization problems developed by Kennedy and Eberhart in 1995 [8]. PSO utilizes a population (called swarm) of particles in the search space. The status of each particle is characterized according to its position and velocity. $\overrightarrow{x_{l}}=\left(x_{i 1}, x_{i 2}, x_{i 3}, \ldots, x_{i d}\right)$, and the velocity of particle $i$ is represented as $\overrightarrow{v_{l}}=\left(v_{i 1}, v_{i 2}, v_{i 3}, \ldots, v_{i d}\right)$. To discover the optimal solution, each particle changes its searching direction according to two factors: The best position of a given particle $x_{l i}$ and the best position obtained by the swarm (global pest) $x_{g}$. PSO searches for the optimal solution by updating the velocity and position of each particle according to the following Equations [9].

$$
\begin{aligned}
& x_{i}(t+1)=x_{i}(t)+v_{i}(t+1) \\
& v_{i}(t+1)=w v_{i}(t)+C_{1} \rho_{1}\left(x_{l i}(t)-x_{i}(t)\right)+C_{1} \rho_{1}\left(x_{g}(t)-x_{i}(t)\right)
\end{aligned}
$$

Where $\mathrm{t}$ denotes the iteration in the evolutionary space, $w$ is the inertia weight, $\mathrm{C} 1$ and $\mathrm{C} 2$ are personal and social learning factors, $\rho_{1}$ and $\rho_{2}$ are random values uniformly distributed within the range $[0,1]$.

The basic process of the PSO algorithm is given as follows:

a. Initialization: Particles are initialized with random positions and velocities.

b. Evaluation: The value of objective function is measured for each particle.

c. Find thex $\mathrm{x}_{\mathrm{li}}$ : If the value of objective function for particle $\mathrm{i}$ is better than the $\mathrm{x}_{\mathrm{li}}$ of particle $\mathrm{i}$, the current value of objective function is set as the new $x_{l i}$ of particle $i$.

d. Find thex $x_{\mathrm{g}}$ : If any pbest is better than the $\mathrm{x}_{\mathrm{g}}, \mathrm{x}_{\mathrm{g}}$ is set to the current value.

e. Update velocity and position: The velocity of each particle is updated according to Equation (1), and the particle is moved to the next position according to Equation (2).

f. Stopping criterion: If the number of iterations is met, the algorithm will be stopped; otherwise it will be returned to step 2 .

\section{PATH LOSS MODEL}

Empirical models describe from a statistical point of view the relationship between the path loss and the environment. Results are usually obtained by means of measurement campaigns. In this paper, we have considered four various Empirical models for our study as follows.

\subsection{Egli Model}

Egli prediction model is an empirical model which has been proposed by [10]. The Egli model is a simplistic model to approach radio-wave path-loss of irregular topography. Based on real data, the path-loss approaching can be formulated as following

$$
\mathrm{PL}=20 \log \left(\mathrm{f}_{\mathrm{c}}\right)+40 \log (\mathrm{d})-20 \log \left(\mathrm{h}_{\mathrm{te}}\right)+\left\{\begin{array}{l}
76.3-10 \log \left(\mathrm{h}_{\mathrm{re}}\right), \mathrm{h}_{\mathrm{re}} \leq 10 \mathrm{~m} \\
85.9-20 \log \left(\mathrm{h}_{\mathrm{re}}\right), \mathrm{h}_{\mathrm{re}} \geq 10 \mathrm{~m}
\end{array}\right.
$$

where

$\mathrm{h}_{\mathrm{te}}=$ height of the base station antenna. Unit: meter (m)

$\mathrm{h}_{\mathrm{re}}=$ height of the mobile station antenna. Unit: meter $(\mathrm{m})$

$\mathrm{d}=$ distance from base station antenna. Unit: meter $(\mathrm{km})$

$\mathrm{f}=$ frequency of transmission. Unit: megahertz $(\mathrm{MHz}$

\subsection{Hata's Model}

This model has been introduced to urban areas; and with some correction factors it could be extended to suburban and rural areas. For urban area the median path loss Equation is given by

$$
\begin{aligned}
& \text { PL(urban })(d B)= \\
& 69.55+26.16 \log (f c)-13.82 \log \left(h_{r e}\right)-a\left(h_{r e}\right)+\left(44.9-\log \left(h_{t e}\right)\right) \log d
\end{aligned}
$$

For suburban area, it is expressed as

$$
\operatorname{PL}(\text { suburban })(\mathrm{dB})=\operatorname{PL}(\text { urban })-2[\log (\mathrm{fc} / 28)] 2-5.4
$$


Finally, for open rural area, it is modified as

$$
\mathrm{PL}(\text { open })(\mathrm{dB})=\mathrm{PL}(\text { urban })-4.78(\log (\mathrm{fc})) 2+18.33 \log (\mathrm{fc})-40.94
$$

In the above Equations, $\mathrm{d}$ is the transmitter-receiver antenna separation distance and it is valid for $1 \mathrm{~km}-20 \mathrm{~km}$, fc represents the operating frequency from150 MHz to $1500 \mathrm{MHz}$. The transmit antenna height, $\mathrm{h}_{\mathrm{re}}$ ranges from $30 \mathrm{~m}$ to $200 \mathrm{~m}$ and the receive antenna height, $\mathrm{h}_{\mathrm{re}}$ ranges from $1 \mathrm{~m}$ to $10 \mathrm{~m}$ are considered [11], [12].

\subsection{Cost 231 Hata model}

The COST 231 is an improved version of the Hata model. It is widely used for predicting path loss in mobile wireless system.It is designed to be used in the frequency band from $1500 \mathrm{MHz}$ to $2000 \mathrm{MHz}$. It also includes corrections for urban, suburban and rural (flat) environments [13],[14].

$$
\begin{aligned}
& \mathrm{PL}(\mathrm{d})(\mathrm{dB})=46.3+33.9 \log \left(\mathrm{f}_{\mathrm{c}}\right)-13.82 \log \left(\mathrm{h}_{\mathrm{te}}\right)-\mathrm{a}\left(\mathrm{h}_{\mathrm{re}}\right)+\left(44.9-6.55 \log \left(\mathrm{h}_{\mathrm{te}}\right)\right) \log (\mathrm{d})+ \\
& \mathrm{C}_{\mathrm{M}}
\end{aligned}
$$

\subsection{SUI Model}

SUI model comes out with three different types of terrain like terrain A dense urban locality, terrain $\mathrm{B}$ has hilly regions and terrain $\mathrm{C}$ for rural with moderate vegetation. The general path loss expression according to the SUI model is given by [15].

$$
P L=A+10 \gamma \log _{10}\left(\frac{d}{d_{0}}\right)+X_{f}+X_{h}+s
$$

Parameter A is defined as follows

$$
A=20 \log \left(\frac{4 \pi d_{0}}{\lambda}\right)
$$

where $\lambda$ is the wavelength in meters. Path loss exponent $\gamma$ given by [16].

$$
\gamma=\mathrm{a}-\mathrm{b} \cdot \mathrm{h}_{\mathrm{te}}+\mathrm{c} / \mathrm{h}_{\mathrm{te}}
$$

The correction factors for the operating frequency and for the receiver antenna height for the model are :

$$
X_{f}=6.0 \log \left(\frac{f_{c}}{2000}\right)
$$

and, for terrain type

$$
\begin{array}{lr}
X_{h}=-10.8 \log \left(\frac{h_{r e}}{2000}\right) ; & \text { for terrain type A and B } \\
X_{h}=-20 \log \left(\frac{h_{r e}}{2000}\right) ; & \text { for terrain type A and B }
\end{array}
$$

Where $\mathrm{f}$, is the frequency in $\mathrm{MHz}$, and $\mathrm{h}_{\mathrm{re}}$ is the receiver antenna height in meters. The SUI model is used for path loss prediction in rural, suburban and urban environments.

\section{MEASUREMENT PROCEDURE AND METHOD OF ANALYSIS}

A drive-test system was used to collect and record signal levels at various locations in a form of logs which were later processed with a communication network analyzer (CNA). During a drive-test some of the system parameters that may be collected are: pilot power strength Ec/Io, forward transmit power Tx, downlink transmit Rx and Frame Error Rate FER. Such a test can be conducted for some identified Base Stations or for the whole network. The drive system measurement tools used were: a Special Mobile Phone (Huawei U6100) GPS receiver (NMEA), a receiving antenna, and a laptop with a key and a drive test software (Huawei GENEX Probe). The vehicle was driven within the base station coverage area while continuously recording the received signal. At every moment of the collected measurements, GPS data is also recorded simultaneously.The emission sites specifications of these bases and their positions are shown in Table 1.

Particle Swarm Optimization for the Path Loss Reduction in Suburban and Rural Area (Messaoud Garah) 
Table1. BTS parameters

\begin{tabular}{|c|c|c|c|}
\hline \multicolumn{2}{|c|}{ Parameters } & $\overline{\text { BTS1 }}$ & $\overline{B T S 2}$ \\
\hline \multicolumn{2}{|l|}{ Region type } & Suburbain & Rural \\
\hline \multicolumn{2}{|l|}{ Transmit power $(\mathrm{dBm})$} & 46 & 43 \\
\hline \multicolumn{2}{|l|}{ Cable Loss + Body loss } & 10.5 & 9.7 \\
\hline \multicolumn{2}{|c|}{ Transmitting antenna gain $(\mathrm{dBi})$} & 17.5 & 16.7 \\
\hline \multicolumn{2}{|c|}{ Receive antenna gain $(\mathrm{dBi})$} & 0 & 0 \\
\hline \multicolumn{2}{|c|}{ Transmit antenna height (m) } & 25 & 35 \\
\hline \multicolumn{2}{|c|}{ Mobile station antenna height (m) } & 1.5 & 1.5 \\
\hline \multicolumn{4}{|c|}{ Operating frequencies $(\mathrm{MHz})$} \\
\hline & Dn-link frequency & 953 & 957,4 \\
\hline \multirow[t]{2}{*}{ Geographic coordinates } & Latitude & 35,2524 & 35,62437 \\
\hline & Longitude & 6,13074 & 6,36984 \\
\hline
\end{tabular}

\section{RESULTS AND DISCUSSION}

\subsection{Comparison with prediction models}

a comparison between predicted path loss and measured path loss have been performed for two base stations BTS1 and BTS2. The performance of the empirical models is then compared to the measured path loss data as in Figures 1 and 2. The values of Mean Error-ME, Root Mean Square Error-RMSE,Standard deviation of error-STD and Relative Error Percentage, are used to measure the forecasting accuracy of these models, are tabulated in Table 2 and Table 3.

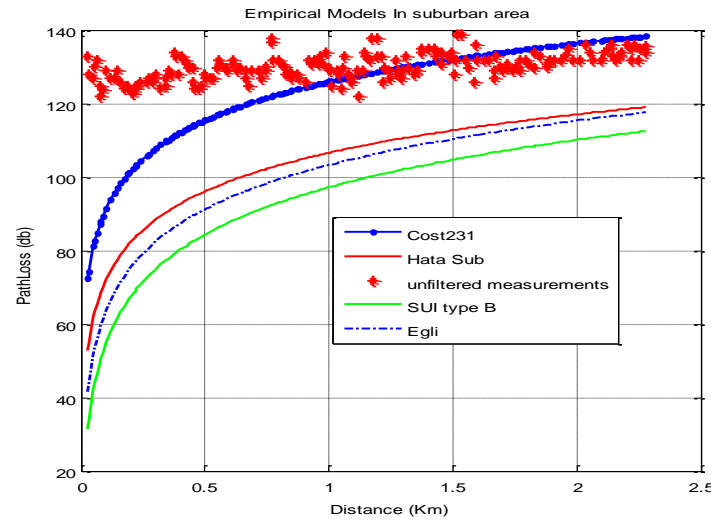

Figure 1. Comparison between predicted and measured path loss for BTS1

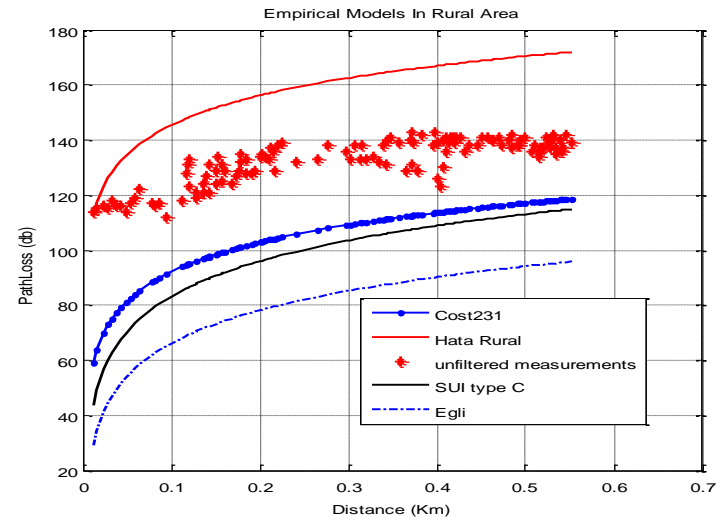

Figure 2. Comparison between predicted and measured path loss for BTS2

From Table 2 and Table 3, it is found that performance of the COST231 Hata model is the best as RMSE and ME are the lowest compared to other models. Figure 1 and Figure 2 consolidate the result that COST231 Hata model is closet to measured path loss than other models.

Table 2. Performance comparison between models used according to test criteria(BTS1)

\begin{tabular}{ccccc}
\hline & rmse & Me & std & re \\
\cline { 2 - 5 } HATA R & 29.0112 & 26.4328 & 0.1452 & 20.4598 \\
Cost 231 & 13.8847 & 8.9197 & 0.1462 & 6.9615 \\
SUI C & 39.4771 & 36.4740 & 0.1427 & 28.2178 \\
EGLI & 33.2731 & 30.1805 & 0.1439 & 23.3654 \\
\hline
\end{tabular}


Table 3. Performance comparison between models used according to test criteria(BTS2)

\begin{tabular}{ccccc}
\hline & rmse & Me & std & re \\
\cline { 2 - 5 } Cost 231 & 26.946 & 26.366 & 0.5886 & 20.1549 \\
HATA R & 27.5175 & 26.949 & 0.6084 & 20.1809 \\
EGLI & 33.5499 & 32.582 & 0.5712 & 24.9922 \\
SUI C & 51.1802 & 50.6988 & 0.5589 & 38.6516 \\
\hline
\end{tabular}

\subsection{Optimization Process by PSO alghorithm}

The COST 231 model is chosen for this study. Formulating the problem to be solved as a single mathematical Equation has five variables as shown in Table 4, assessed by a cost function to a stopping criteria depends on the performance thereof. And this cost function is generally defined as the RMSE (Root Mean Square Error).

COST 231(rural/sub) model is defined as

$$
\begin{aligned}
& \mathrm{PL}=46.3+33.9 \log \left(\mathrm{f}_{\mathrm{c}}\right)-13.82 \log \left(\mathrm{h}_{\mathrm{te}}\right)-\mathrm{a}\left(\mathrm{h}_{\mathrm{re}}\right)+\left(44.9-6.55 \log \left(\mathrm{h}_{\mathrm{te}}\right)\right) \log (\mathrm{d}) \\
& +\mathrm{C}_{\mathrm{M}} \\
& \mathrm{a}\left(\mathrm{h}_{\mathrm{re}}\right)=\left(1.1 \log \left(\mathrm{f}_{\mathrm{c}}\right)-0.7\right) \mathrm{h}_{\mathrm{re}}-\left(1.56 \log \left(\mathrm{f}_{\mathrm{c}}\right)-0.8\right) \\
& \mathrm{C}_{\mathrm{M}}=0
\end{aligned}
$$

It can be written as follows

$$
\begin{aligned}
& \mathrm{PL}=46.3+44.9 \log (\mathrm{d})-13.82 \log \left(\mathrm{h}_{\mathrm{te}}\right)-6.55 \log \left(\mathrm{h}_{\mathrm{te}}\right) \log (\mathrm{d})+33.9 \log \left(\mathrm{f}_{\mathrm{c}}\right)- \\
& \mathrm{a}\left(\mathrm{h}_{\mathrm{re}}\right)
\end{aligned}
$$

Table 4. The optimized parameters

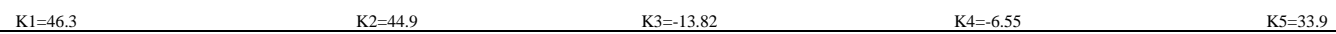

The fitness function used for parameters adjustment is defined by the mean square error (RMSE) as:

$$
\operatorname{RMSE}=\sqrt{\frac{\sum_{\mathrm{i}=1}^{\mathrm{n}}\left|\mathrm{PL}_{\mathrm{m}, \mathrm{i}}-\mathrm{PL}_{\mathrm{i}}\right|^{2}}{\mathrm{n}}}
$$

Where $\mathrm{PL}_{\mathrm{m}}$ represents the measured path loss in $\mathrm{dB}, \mathrm{PL}$ is the predicted path loss in $\mathrm{dB}$, and $\mathrm{n}$ is the number of the measured data points.

\subsubsection{Optimization results by PSO}

Simulation results using the PSO Alghorithm are presented in the following Figure 3, Figure 4, Table 5 and Table 6.

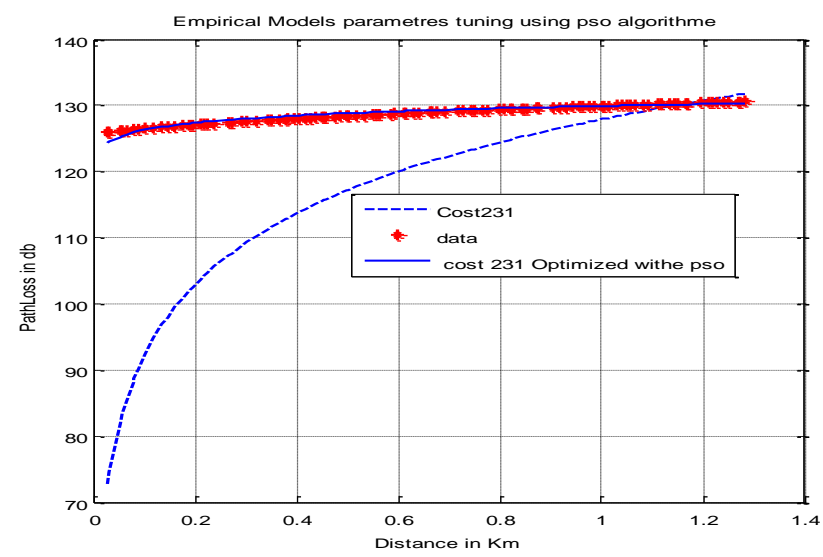

Figure 3. Comparison between COST-231 Hata and COST231-Opt (suburban) 


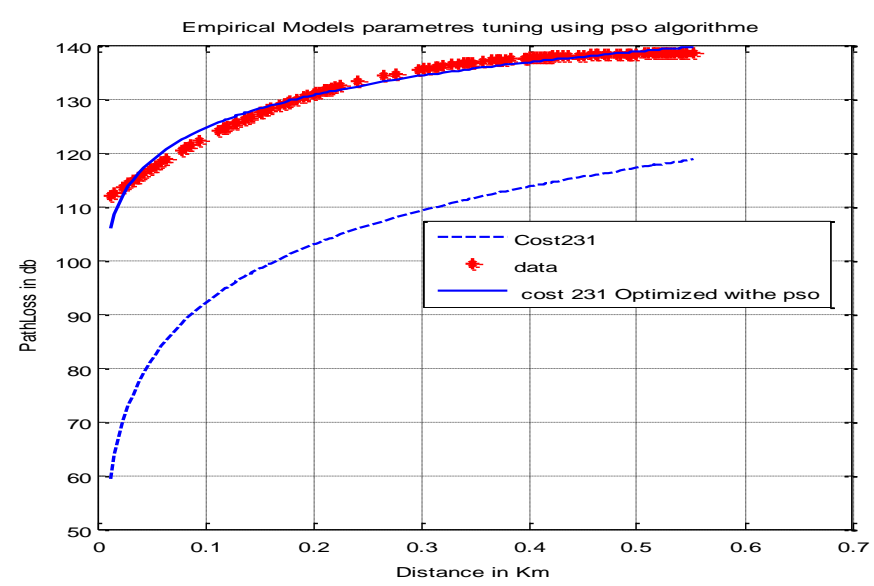

Figure 4. Comparison between COST-231 Hata and COST231-Opt (rural)

Table 5. Results of the optimization process for COST-231Hata model (suburban)

\begin{tabular}{cccc}
\hline & & Cost231-opt & Cost231 \\
\hline Parametres & K1 & 27.1267 & 46.3 \\
& K2 & 14.5035 & 33.9 \\
& K3 & 19.6153 & 13.82 \\
& K4 & -6.9221 & 44.9 \\
& K5 & 25.5010 & 6.55 \\
RMSE & & 0.7688 & 16.1158 \\
Time of calculation (s) & & 10.1830 & $/$ \\
\hline
\end{tabular}

Table 6. Results of the optimization process for COST-231Hata model (rural).

\begin{tabular}{cccc}
\hline & & Cost231-opt & Cost231 \\
\hline Parametres & K1 & 25.9280 & 46.3 \\
& K2 & 5.7622 & 33.9 \\
& K3 & 26.5562 & 13.82 \\
K4 & 10.3980 & 44.9 \\
& K5 & 27.4992 & 6.55 \\
& & 1.1172 & 27.2553 \\
RMSE & 9.1150 & $/$ \\
\hline
\end{tabular}

Beginning with the results of Table 5 and Table 6 and passing through the two Figures 3 and 4, we have noticed that both optimized models in rural and suburban area surpass other models in terms of overall performance.

\section{CONCLUSION}

In this paper, the measured path losses in two cells are compared with theoretical path loss models: Hata, SUI, Lee and Egli. Based on this, an optimized COST-231 Hata model for the prediction of path loss in Rural and Suburban environments of Batna city (Algeria) is developed. From the numerical example, a new values of parameters are proposed for COST-231 Hata model based on measured data. It is obvious that adjusted COST-231 Hata model shows the closest agreement with the measurement result. Hence COST-231 Hata model with proposed modification is recommended for rural and suburban area of Batna city.

\section{REFERENCES}

[1] Torres J, Guardado J.L, Rivas-Dávalos F, Maximov S, Melgoza E, "A Genetic Algorithm Based on the Edge Window Decoder Technique To Optimize Power Distribution Systems Reconfiguration”, Electrical Power and Energy Systems, vol. 45, pp.28-34, 2013. 
[2] Carreno E., Romero R, Padilha-Feltrin A, "An Efficient Codification to Solve Distribution Network Reconfiguration for Loss Reduction Proble”, IEEE Trans Power Syst, vol. 3, pp. 42-51, 2008.

[3] Famoriji J, Olasoji Y, "Radio Frequency Propagation Mechanisms and Empirical Models for Hilly Areas", International Journal of Electrical and Computer Engineering (IJECE) vol. 3, pp. 372-3763, 2013.

[4] Imran I, Mustafa S, Mahmood AK, Shahzad A. Malik, Shahid A, "Path Loss Modeling of WLAN and WiMAX System”, International Journal of Electrical and Computer Engineering (IJECE), vol .5, pp. 1083-1091, 2015.

[5] M.Garah et al, "Path Loss Models Optimization for Mobile Communication in Different Areas" , Indonesian Journal of Electrical Engineering and Computer Science, vol.3, pp.126-135, july2016.

[6] Tahcfulloh S, Riskayadi E, "Optimized Suitable Propagation Model for GSM 900 Path Loss Prediction”,TELKOMNIKA Indonesian Journal of Electrical Engineering, vol.14, pp. 154-162, 2015.

[7] Surajudeen Bakinde N, Faruk N, Ayeni A, Muhammad M, Gumel M, "Comparison of Propagation Models for GSM 1800 and WCDMA Systems in Selected Urban Areas of Nigeria", International Journal of Applied Information Systems (IJAIS), Vol. 13, pp. 6-13, 2012.

[8] J. Kennedy, R. Eberhart, "Particle swarm optimization", Proceedings of the IEEE International Conference on Neural Networks, (ICNN), vol. 4, pp. 1942-1948, 1995.

[9] Y. Shi, R. Eberhart, “A Modified Particle Swarm Optimizer”, Evolutionary Computation Proceedings, 1998. IEEE World Congress on Computational Intelligence, IEEE, pp. 69-73, May 1998.

[10] Egli J. J, “Radio Propagation above 40 Mc over Irregular Terrain”, Proc. IRE, vol.45 no10, pp.1383-1391,1957.

[11] Sarkar T. K., et al, "A Survey of Various Propagation Models For Mobile Communication”,IEEE Antennas and Propagation Magazine, vol.45, pp. 51-82, 2003.

[12] Hata M, "Empirical Formula for Propagation Loss in Land Mobile Radio Service", IEEE Trans. Veh. Technol, vol. 29 no 3, pp. 317-325, 1980.

[13] Parsons J. D, “The Mobile Radio Propagation Channel”, 2nd ed,Wiley,West Sussex 2000.

[14] Asztalos T, "Planning a WiMAX Radio Network with A915. Alcatel-Lucent COST Action 231. Digital mobile radio towards future generation systems", final report, tech. rep, European Communities, EUR 18957,1999.

[15] H. R. Anderson, "Fixed Broadband Wireless System Design”, John Wiley and Sons Ltd, 2003.

[16] Erceg V., Greenstein L. J, "In Empirically based Path Loss Model for Wireless Channels in Suburban Environments", IEEE Journal on Selected Areas of Communications, vol.17, pp. 1205-1211, 1999. 